\title{
AGE-RAGE Stress in the Pathophysiology of Pulmonary Hypertension and its Treatment
}

\author{
Kailash Prasad, MBBS (Hons), MD, PhD, DSc, FRCPC, FACC, FIACS, FICA ${ }^{1}$ \\ ${ }^{1}$ Department of Physiology, College of Medicine, University of \\ Saskatchewan, Saskatoon, Canada \\ Int J Angiol 2019;28:71-79.

\begin{abstract}
Address for correspondence Kailash Prasad, MBBS (Hons), MD, PhD, DSC, FRCPC, FACC, FIACS, FICA, Department of Physiology, College of Medicine, University of Saskatoon, 107 Wiggins Road, Saskatoon, SK, S7N 5E5, Canada (e-mail: k.prasad@usask.ca).
\end{abstract}

\author{
Abstract \\ Keywords \\ - advanced glycation \\ end products \\ - cell receptor for AGE \\ - soluble RAGE \\ - pulmonary \\ hypertension \\ - pathogenesis \\ - therapeutic targets
}

Pulmonary hypertension ( $\mathrm{PH})$ is a rare and fatal disease characterized by elevation of pulmonary artery pressure $\geq 25 \mathrm{~mm} \mathrm{Hg}$. There are five groups of $\mathrm{PH}$ : (1) pulmonary artery (PA) hypertension (PAH), (2) PH due to heart diseases, (3) PH associated with lung diseases/hypoxia, (4) PH associated with chronic obstruction of PA, and (5) PH due to unclear and/or multifactorial mechanisms. The pathophysiologic mechanisms of group 1 have been studied in detail; however, those for groups 2 to 5 are not that well known. PH pathology is characterized by smooth muscle cells (SMC) proliferation, muscularization of peripheral PA, accumulation of extracellular matrix (ECM), plexiform lesions, thromboembolism, and recanalization of thrombi. Advanced glycation end products (AGE) and its receptor (RAGE) and soluble RAGE (sRAGE) appear to be involved in the pathogenesis of PH. AGE and its interaction with RAGE induce vascular hypertrophy through proliferation of vascular SMC, accumulation of ECM, and suppression of apoptosis. Reactive oxygen species (ROS) generated by interaction of AGE and RAGE modulates SMC proliferation, attenuate apoptosis, and constricts PA. Increased stiffness in the artery due to vascular hypertrophy, and vasoconstriction due to ROS resulted in $\mathrm{PH}$. The data also suggest that reduction in consumption and formation of AGE, suppression of RAGE expression, blockage of RAGE ligand binding, elevation of sRAGE levels, and antioxidants may be novel therapeutic targets for prevention, regression, and slowing of progression of PH. In conclusion, AGE-RAGE stress may be involved in the pathogenesis of $\mathrm{PH}$ and the therapeutic targets should be the AGE-RAGE axis.
Pulmonary hypertension ( $\mathrm{PH})$ is a rare and fatal disease characterized by elevation of the mean pulmonary artery pressure $\geq 25 \mathrm{~mm} \mathrm{Hg}$ at rest or $\geq 30 \mathrm{~mm} \mathrm{Hg}$ with exercise and is due to remodeling of the vasculature of the pulmonary artery and increased vasoconstriction. This disease is characterized by dyspnea initially while exercising, fatigue, dizziness or fainting, chest pressure or pain, edema of ankles, legs, ascites, cyanosis, and increased heart rate. If left untreated, it results in right ventricular failure and ultimately death. ${ }^{1}$ PH has been classified as pulmonary artery hypertension (PAH), and $\mathrm{PH}$ due to left heart disease, lung disease and/or hypoxia, unclear multifocal mechanisms, and chronic thromboembolism. ${ }^{2}$ The incidence of portopulmonary hypertension due to cirrhosis of the liver is high compared to other types of hypertension. ${ }^{3}$ The annual incidence of adult PH from the period of 2003 to 2012 increased from 24.1 to 28.7 cases/100,000 population, and the annual prevalence from the period of 1993 to 2012 increased from 98.8 to 127.3 cases $/ 100,000$ population, respectively. ${ }^{4}$ Except for $\mathrm{PAH}$ the epidemiology of PH is largely unknown.

Advanced glycation end products (AGE) and its receptor RAGE (receptor for AGE) have been implicated in the pathophysiology of numerous diseases including systemic hypertension $^{5}$ and carotid artery stenosis. ${ }^{6}$ Based on the involvement 
of the AGE-RAGE axis in various diseases, modulation of AGE and RAGE has been proposed for the treatment of diseases related to the AGE-RAGE axis. ${ }^{6,7}$ Epidemiology, classification, hemodynamics, pathogenesis, the AGE-RAGE axis and treatment modalities of $\mathrm{PH}$ have been addressed in this review. Special attention has been given to the role of AGE-RAGE stress in the pathophysiology of $\mathrm{PH}$ and its treatment with reduction in AGE-RAGE stress.

\section{Epidemiology}

The prevalence of PAH and idiopathic PAH is 15 cases and 5.9 cases/1 million adult population, respectively. The incidence $\mathrm{PAH}$ is 2.4 cases/ 1 million adult population/year. ${ }^{8,9}$ The incidence of PAH ranged from 1.1 to 7.6/1 million, and prevalence ranged from 6.6 to 26.1/1 million for European countries, like France, U.K., Ireland, and Spain. ${ }^{10}$ The prevalence of PH is up to $60 \%$ in patients with left ventricular systolic dysfunction, and up to $70 \%$ in patients with isolated left ventricular diastolic dysfunction. ${ }^{11}$ The incidence of $\mathrm{PH}$ is $20 \%$ in chronic obstructive pulmonary disease (COPD) patients with respiratory failure, ${ }^{12}$ but in advanced COPD the incidence is greater than $50 \%{ }^{13}$ The incidence of $\mathrm{PH}$ is $39 \%$ in patients with interstitial lung disease. ${ }^{14}$ The incidence and prevalence of $\mathrm{PH}$ in chronic pulmonary thromboembolism in the Spanish population is 0.9 case/ 1 million/year, and 3.2 cases/ 1 million, respectively. ${ }^{15}$ The incidence of $\mathrm{PH}$ after acute pulmonary embolism is 1.0 to $3.8 \%{ }^{16}$ The prevalence of $\mathrm{PH}$ in sarcoidosis is 1 to $28 \%{ }^{17}$

\section{Classification of PH}

The clinical classification of $\mathrm{PH}$ has been updated. ${ }^{1} \mathrm{PH}$ has been classified into five groups:

1. PAH that covers idiopathic, heritable, drug-and toxininduced, associated with connective tissue diseases, HIV (human immunodeficiency virus) infection, portal hypertension, congenital systemic to pulmonary shunts, schistosomiasis, PAH responders to calcium channel blockers, persistent pulmonary hypertension of newborn syndrome, and associated with venous/capillaries (pulmonary venoocclusive disease, pulmonary capillary hemangiomatosis).

2. PH due to left heart diseases, such as heart failure, valvular heart diseases, and congenital/acquired cardiovascular conditions, leading to post capillary $\mathrm{PH}$.

3. PH associated with lung diseases and/or hypoxia that include COPD, interstitial lung diseases, and hypoxia without lung diseases.

4. PH related to chronic obstruction of pulmonary artery, such as chronic thromboembolism and other pulmonary artery obstruction.

5. PH due to unclear and/or multifactorial mechanisms that covers hematological disorders.

\section{Hemodynamics of PH}

Pulmonary hypertension is defined as mean pulmonary arterial pressure (mPAP) $\geq 25 \mathrm{~mm} \mathrm{Hg}$ measured by right heart catheterization, pulmonary capillary wedge pressure (PCWP) $\leq 15 \mathrm{~mm} \mathrm{Hg}$ and pulmonary vascular resistance (PVR) $\geq 240$ dynes $/ \mathrm{s} / \mathrm{cm}{ }^{5}$ Doppler's echocardiography, although correlate with right ventricular systolic pressure, they are not precise and are not substitute for accurate PAP measured by cardiac catheterization. ${ }^{18}$ The abnormal elevation of mPAP in isolation is not adequate to define MPAP because it can be due to an increase in cardiac output or pulmonary capillary wedge pressure (PCWP). Hemodynamically $\mathrm{PH}$ is classified as precapillary and postcapillary $\mathrm{PH} .{ }^{19}$ In precapillary $\mathrm{PH}, \mathrm{mPAP}$ is $\geq 25 \mathrm{~mm} \mathrm{Hg}$, PCWP is $\leq 15 \mathrm{~mm} \mathrm{Hg}$, and PVR is $\geq 240$ dynes $/ \mathrm{s} / \mathrm{cm}^{5}$ and cardiac output is normal or reduced. Clinically $\mathrm{PAH}$, and $\mathrm{PH}$ due to lung diseases, chronic thromboembolism, and unclear and/or multifactorial groups belong to this class. Hemodynamically, PH due to left heart disease is classified as postcapillary $\mathrm{PH}$ where mPAP is $\geq 25 \mathrm{~mm} \mathrm{Hg}$, PCWP is $\geq 15 \mathrm{~mm} \mathrm{Hg}$, and PVR is $<240$ dynes $/ \mathrm{s} / \mathrm{cm}^{5}{ }^{5}$ cardiac output is normal or reduced and passive transpulmonary pressure gradient (TPG; mPAP-mPCWP) is $\leq 12 \mathrm{~mm} \mathrm{Hg}$, and reactive TPG is greater than $12 \mathrm{~mm} \mathrm{Hg}$.

\section{Pathology of PH}

Pulmonary hypertension is characterized by smooth muscle cells proliferation, muscularization of peripheral pulmonary arteries, and medial thickening of larger pulmonary arteries. Muscularization is associated with fibroblastosis, reduced responses to vasodilators, and formation of obliterative plexiform lesions. The pathophysiologic mechanisms of group 1 (PAH) have been studied in detail. However, the pathophysiologic mechanisms of groups 2 to 5 PH are not that well known. The histopathological studies, such as vasculopathy, hypertrophy of media, intimal hyperplasia and fibrosis, plexiform lesions, recanalization of thrombi, and thromboembolism, are similar in all the five groups irrespective of the differences in etiology. Increased vascular resistance in PAH is due to vasoconstriction, vascular remodeling, and thrombosis. ${ }^{20}$ Since the etiologies are different for each group, the author would like to describe the pathophysiology of each group in short. Group 1 (PAH): in this group, distal pulmonary artery is affected. The medial hypertrophy, intimal proliferation and fibrosis, adventitial thickening, inflammatory infiltration, and plexiform and thrombotic lesions characterize lesion. The mechanisms of these pathological changes are multifactorial. Hypoxia-induced pulmonary vasoconstriction leads to luminal narrowing. Hypoxia also inhibits voltage-gated potassium channel in the smooth muscle cells of pulmonary artery leading to the opening of the voltage-gated calcium channel. ${ }^{21}$ This would constrict the pulmonary artery causing dysfunction of pulmonary arterial endothelial cells resulting in decreased production of vasodilators (prostacyclin, nitric oxide [NO]), and increased production of vasoconstrictors (endothelin-1, thromboxane $\mathrm{A}_{2}$ ). ${ }^{22}$ Pulmonary vascular remodeling is comprised of medial hypertrophy due to proliferation of smooth muscle cells of the pulmonary artery and neointimal formation due to dysfunction and proliferation of endothelial cells. ${ }^{23}$ Elevated production of the adventitial matrix and reduction in proteolysis of the extracellular matrix (ECM) would also contribute in remodeling of the pulmonary 
artery. $^{22}$ Platelets are also involved in the pathogenesis of PAH because they occlude the vessels through thrombosis and generation of NO, a vasoconstrictor. ${ }^{24}$ Abnormal platelets from patients with $\mathrm{PAH}$ have been shown to reduce the levels of endothelial NO synthase. ${ }^{25}$ Plasma serotonin concentrations are higher in patients with PAH because of abnormal platelet processing and storage. Serotonin is a vasoconstrictor and a proliferator of smooth muscle cells. Group2: pathological changes in this group include enlarged and thick pulmonary veins, dilated pulmonary capillaries, interstitial edema, alveolar hemorrhage and the enlargement of lymphatic vessels, and lymph nodes. ${ }^{19}$ There may be medial hypertrophy and intimal fibrosis in the distal pulmonary artery. Group 3: pathological changes in this group include medial hypertrophy and intimal proliferation of the distal pulmonary artery. ${ }^{19}$ Group 4: pathological lesions in this group are characterized by organized thrombi attached to inner pulmonary arterial wall, plexiform lesions, and collateral circulation from systemic arteries. ${ }^{19}$ Group 5: pathological changes in this group are heterogeneous and variable. $^{19}$

\section{AGE-RAGE Stress in the Pathogenesis of Pulmonary Hypertension}

Recently, attention has been focused on the role of AGE and RAGE and the circulating sRAGE in the pathophysiology of pulmonary hypertension. The following sections describe the AGE-RAGE axis, AGE-RAGE stress, serum/plasma levels of AGE and SRAGE, and the levels of cell-bound RAGE in patients with $\mathrm{PH}$.

\section{AGE-RAGE Axis}

AGEs are heterogeneous groups of irreversible adducts formed by nonenzymatic glycation of proteins, lipids, and nucleic acid with reducing sugars. ${ }^{26,27}$ AGE interacts with its cell-bound receptor RAGE to generate reactive oxygen species (ROS) ${ }^{28}$ which in turn activates nuclear factor kappa B (NF- $k \mathrm{~B}){ }^{29}$ Activated NF- $k$ B activates numerous genes including proinflammatory cytokines, ${ }^{30}$ and adhesion molecules. ${ }^{31}$ RAGE is a multiligand receptor which can bind with many ligands. There are two isoforms of RAGE: cleaved RAGE (cRAGE), and endogenous secretory RAGE (esRAGE). cRAGE is proteolytically cleaved from full length RAGE, ${ }^{32}$ while esRAGE is produced from splicing of full length RAGE mRNA. ${ }^{33}$ Measurements of sRAGE include both cRAGE and esRAGE. sRAGE acts as a decoy for RAGE by binding with RAGE ligand. ${ }^{34}$ sRAGE binding with ligands does not activate intracellular signaling. SRAGE is cytoprotective because it protects from the adverse effects of interaction of RAGE with ligands.

\section{AGE-RAGE Stress}

In the AGE-RAGE axis which is comprised of AGE, RAGE, and SRAGE, AGE and RAGE are coined as stressors, while sRAGE, enzymatic degraders of AGE (glyoxalase-1, glyoxalase-2), receptor-mediated degraders of AGE (AGER-1, AGER-2), and factors that lower the blood levels of AGE have been coined as antistressors. ${ }^{35}$ The ratio of stressors/antistressors has been termed as AGE-RAGE stress. ${ }^{35}$ The ratio of AGE/ SRAGE has been proposed as a simple and feasible measure of AGE-RAGE stress. ${ }^{35} \mathrm{~A}$ high index of AGE/sRAGE would result in tissue damage and the development of diseases.

\section{Serum Levels of AGE in PH}

Serum/plasma levels of AGE in patients with PH are not available in literature. However, serum/plasma levels of AGE in diseases associated with PH are known. Plasma levels of AGE (carboxymethyl lysine [CML]) are elevated in COPD patients compared with non-COPD patients. ${ }^{36}$ AGE levels are elevated in the lungs of patients with COPD. ${ }^{37}$ The AGE levels are elevated in the skin of COPD patients. ${ }^{38}$ Serum levels of AGE are significantly increased in patients with left ventricular diastolic dysfunction in type 1 diabetes ${ }^{39,40}$ and heart failure. $^{41,42}$

\section{Levels of RAGE in PH}

The RAGE in endothelial cells of large and small pulmonary arteries, neointimal proximal remodeled pulmonary arteries, recanalized vessel-like structure of distal endarterectomized chronic thromboembolism PH (CTEPH) and idiopathic PAH (iPAH) were differently expressed. ${ }^{43}$

There is an increased expression of RAGE in smooth muscle cells of the pulmonary artery under hypoxic conditions in both humans and mice. ${ }^{44}$ These authors also showed that the expression of RAGE was upregulated in pulmonary artery in hypoxia plus Sugen5416 (SU5416)-induced PAH mice. They also demonstrated that RAGE deletion reduced the PA pressure and restrained ECM accumulation in PA of the mouse model. Blocking RAGE activity with neutralizing antibody or genetic deletion of RAGE reduced ECM protein accumulation. ${ }^{44}$ RAGE is one of the most upregulated proteins in $\mathrm{PAH}$ lung tissue of $\mathrm{PAH}$ patients. ${ }^{45}$ There is an increase in the RAGE mRNA levels in human pulmonary hypertensive lung tissue compared with normotensive lung tissue, and an increase in RAGE protein levels in pulmonary artery in human pulmonary hypertensive patients compared with normotensive pulmonary artery (five-fold increase). ${ }^{46}$ They also showed that that there was no upregulation of RAGE in other tissue (brain, kidney, and peripheral muscle). Increased RAGE activation by its ligands including AGE increases RAGE expression. ${ }^{28}$ It is possible that the increases in AGE in PH could increase the expression of RAGE. The data suggest that RAGE levels are elevated in patients with $\mathrm{PH}$.

\section{Serum/Plasma Levels of sRAGE in PH}

Serum levels of sRAGE are variable in PH. Plasma levels of SRAGE were significantly lower in patients with idiopathic pulmonary fibrosis and interstitial lung disease. ${ }^{47}$ Serum SRAGE levels are reduced in patients with emphysema. ${ }^{48}$ Serum levels of SRAGE were lower in patients with COPD than the levels in control. ${ }^{38}$ However, there are reports where sRAGE levels have been higher in PH patients compared with 
controls. Plasma levels of sRAGE have been reported to be higher in patients with PH and CTEPH than those in controls. ${ }^{49}$ Serum levels of sRAGE and esRAGE were higher in patients with iPAH and CTEPH compared with control subjects. ${ }^{43}$ The discrepancy in the serum levels of sRAGE might be due to the type of patients. High levels of sRAGE were in patients with pulmonary hypertension, while the low levels of sRAGE were in patients with lung diseases without hypertension.

\section{Mechanism of AGE-RAGE-Induced Pulmonary Hypertension}

Remodeling of pulmonary artery in PAH is due to enhanced proliferation and resistance to apoptosis of pulmonary artery smooth muscle cells. Since the histopathology of PH includes intimal hyperplasia due to an increase in the proliferation of smooth muscles and fibrosis, the focus will be on the role of AGE, RAGE, and sRAGE on smooth muscle proliferation and fibrosis. Attention will also be given to the vasoconstrictor effect of the AGE-RAGE axis. Stiffness of the pulmonary artery is due to the increased amounts of collagen, glycation of collagen, and cross-linking of collagen with AGEs. AGEs are formed in the proteins of ECM. Accumulation of AGE on protein of ECm leads to the formation of cross-link which traps other local macromolecules. ${ }^{50}$ Cross-linking of collagen and elastin increases the ECM area which increases the stiffness of the artery. ${ }^{51}$ Glycation also increases the synthesis of collagen. ${ }^{52}$ There is cross-linking of elastin with AGE which reduces the elasticity of arteries. Matrix-bound AGE inhibits antiproliferative activity of $\mathrm{NO}^{53}$ reduce half-life of NO synthase, ${ }^{54}$ impair NO production, ${ }^{55}$ inactivates ${ }^{50},{ }^{56}$ reduces the production of prostacycline, ${ }^{57}$ and increases the expression of endothelin-1. ${ }^{58}$ AGE promotes proliferation and suppresses autophagy via reduction in cathepsin D in vascular smooth muscle cells. ${ }^{59}$ AGE promotes proliferation and migration of primary rat vascular smooth muscle cells via oxidative stress. ${ }^{60}$ The above data suggest that AGE can increase thickness and resistance of the pulmonary artery through increasing the matrix of blood vessels.

As described earlier, RAGE is a multiligand receptor and combines with ligands, such as AGE, high mobility group box-1 (HMGB-1), and calcium binding calgranulin-like protein S100A4 (S100). S100 protein family consists of 24 members. Extracellular S100A4 is one of the 24 members of S100. RAGE has been implicated to play a role in many signaling pathways, such as inflammation, proliferation, and migration, all of which are associated with pathology of $\mathrm{PH}^{46}$ The AGE-RAGE interaction leads to the generation of ROS, and the proliferation and autophagy in vascular smooth muscle cells. ${ }^{61}$ In vitro, S100A4 produces proliferation of human pulmonary arterial smooth muscle cells via an action non-RAGE. ${ }^{62}$ RAGE mediates deposition of ECM fibronectin and collagen through activation of transforming growth factor- $\beta 1 .{ }^{44}$ Vascular remodeling of the PA in PAH is characterized by deposition of ECM. ${ }^{63}$ Binding of RAGE with HMGB-1 induces proliferation and migration of fibroblasts which are prevented by RAGE antibody. ${ }^{64}$ RAGE regulates the metabolic reprogramming-induced over-proliferation in pulmonary hypertension. ${ }^{65}$ Recently, it has been shown that RAGE plays a crucial role in inappropriate increase in pulmonary arterial smooth muscle cells in PAH. ${ }^{66}$ These above data suggest that AGE and its interaction with RAGE would muscularize the pulmonary artery, induce medial thickness and fibrosis, and increase stiffness in the pulmonary artery.

AGE-RAGE interaction increases the generation of reactive oxygen species including Superoxide anion, hydrogen peroxide, and hydroxyl radicals. Superoxide anion produces contraction of isolated rabbit aorta which is endotheliumdependent and is partially mediated by arachidonic acid metabolism. ${ }^{67} \mathrm{H}_{2} \mathrm{O}_{2}$ in lower concentration produces contraction, while in higher concentration, it produces transient relaxation followed by contraction of isolated rabbit aorta. ${ }^{68}$ In vivo, ROS generated by polymorphonuclear leucocytes and administration of oxygen radicals increase total peripheral vascular resistance. ${ }^{69,70}$ Oxidative stress plays a key role in the pathogenesis of pulmonary components of COPD. ${ }^{71}$ COPD patients have levels of ROS in plasma and endothelial cells compared with control subjects. Emerging evidence demonstrates the role of ROS in PH pathology. ROS modulates cellular proliferation and attenuates apoptosis. ${ }^{72}$ ROS plays a role in mediating vasoconstrictor reactivity and pulmonary hypertension in both chronic hypoxia and hypoxia/SU5416 rat model. ${ }^{73}$ AGE-RAGE-induced generation of ROS increases the pulmonary arterial pressure directly and through hypertrophy of pulmonary artery. The above data suggest that AGE and its interaction with RAGE play a crucial role in pathogenesis of $\mathrm{PH}$.

\section{Therapeutic Approaches Targeting AGE- RAGE Axis for Pulmonary Hypertension}

Current treatment of pulmonary hypertension has progressed due to pulmonary hypertension-targeted drugs. However, long-term survival of patients with PAH is still suboptimal. A search for new treatment modalities that can reverse pulmonary artery remodeling is on. Lately, attention has been focused on the AGE-RAGE axis because it is involved the pathogenesis of PH. AGE-RAGE axis (AGE, RAGE, and sRAGE) is an important therapeutic target. Reduction in AGE and RAGE levels, elevation of sRAGE levels and antioxidant are promising new therapeutic strategies in $\mathrm{PH}$.

\section{Reduction in the AGE levels}

AGE levels in the body can be lowered by reducing dietary consumption of AGE, preventing AGE formation and increasing AGE degradation.

\section{Reduction in Dietary Consumption of AGE}

Glucose consumption should be reduced because glucose is involved in the synthesis of AGE. ${ }^{27}$ Consumption of high AGErich diets ${ }^{74}$ including, red meat, cheese, cream, butter, and animal fat those have higher amounts of AGE than oil and nuts should be reduced. Consumption of diets, such as butter, cream, cheese, margarine, and mayonnaise, those have highest amount of AGE should also be reduced. ${ }^{75}$ These authors also reported that beef has the highest amount of AGE, 
followed by poultry, pork, fish, and eggs. Diets with the lowest amount of AGE, ${ }^{75}$ such as grains, legumes, vegetables, fruits, and milk, should be consumed. ${ }^{75}$ Fat-free milk has lower amounts of AGE than whole milk. Cooking at high temperatures in dry heat should be avoided or markedly reduced because it increases the formation of AGE. Frying, broiling, grilling, and roasting generates more AGE than poaching, stewing, steaming, and boiling. ${ }^{75}$ There is a reduction in AGE formation when cooking for short duration in moist heat at low temperature. ${ }^{75}$ Short-term restriction of dietary AGE has been reported to significantly reduce the serum levels of AGE in healthy or diabetic individuals. ${ }^{76}$ Hence, foods should not be cooked at high temperature in dry heat. Cigarette smoking should be stopped because it increases serum levels of AGE. ${ }^{77}$

\section{Prevention of AGE formation}

There are numerous vitamins which inhibit the formation of AGE. Benfotiamine (vitamin B1 derivative), ${ }^{78}$ pyridoxine, ${ }^{79}$ vitamins $C,{ }^{80} \mathrm{D},{ }^{81}$ and $\mathrm{E}^{82}$ prevent the formation of AGE. Use of these vitamins may help the patients with $\mathrm{PH}$. Carnosine inhibits the formation of AGE through acting as an antioxidant, ${ }^{83}$ a chelating agent for metal ions, ${ }^{84}$ and reacting with the carbonyl group of methylglyoxal (MG)-modified proteins resulting in protein-carbonyl-carnosine adducts. Carnosine modified AGE becomes ineffective to interact with RAGE. ${ }^{85}$ Acidic ingredients, such as lemon juice or vinegar, ${ }^{86}$ and pomegranate and its phenolic components 87 inhibit the formation of AGE. The patients with $\mathrm{PH}$ should be advised to consume the above agents.

\section{Degradation of AGE}

AGE is degraded in the body in two ways: enzymatic degradation and AGE-receptor-mediated degradation. Glyoxalase1 and glyoxalase-2 degrade AGE. ${ }^{88}$ Overexpression of glyoxalase- 1 in bovine endothelial cells completely prevented hyperglycemia-induced AGE formation. ${ }^{89}$ AGE receptor mediated degradation of AGE is accomplished by AGE receptor-1 (AGER-1), AGER-2, and AGER-3. ${ }^{35,90}$ AGER-1 increases the uptake and removal of AGE and blocks AGE-RAGE mediated production of ROS and cytokines. ${ }^{90}$ Drugs should be developed to overexpress the above enzymes and receptors to reduce the levels of AGE.

\section{Antagonist of RAGE}

RAGE is antagonized by the suppression of its expression, blockage of ligand binding, and inhibition of RAGE signal transduction to antagonize RAGE receptor.

\section{Downregulation of RAGE expression}

Lipid lowering agents (simvastatin, ${ }^{91}$ and atorvastatin ${ }^{92}$ ), angiotensin-II receptor blockers (telmisartan ${ }^{93}$ and cande$\operatorname{sartan}^{94}$ ), antidiabetic agent (thiazolidinediones ${ }^{95}$ ), calcium channel blocker(nefedipine ${ }^{96}$ ), and curcumin ${ }^{97}$ downregulate the RAGE expression. Most of the above-mentioned drugs except curcumin are being used for the treatment of certain diseases and will have additional benefits. Meloche et $\mathrm{al}^{46}$ has reported that RAGE inhibition by RAGE siRNA selectively delivered to the lungs of monocrotaline and Sugen-hypoxia-induced pulmonary hypertension in rats reversed the pulmonary hypertension. This shows that suppression of RAGE expression can indeed reverse the pulmonary hypertension.

\section{Blockers of RAGE Ligand Binding}

Recently new drugs have been developed to block RAGE ligand binding for the treatment of Alzheimer's disease. The drugs TTP488 or PF-04494700, also known as Azeliragon, and TTP4000 prevent RAGE ligand from interacting with RAGE. ${ }^{98}$ These new drugs has been shown to be of benefit in patients with Alzheimer's disease. These drugs have not been tried in patients with $\mathrm{PH}$. Inhibitors of RAGE have been discussed in detail by Bongarzone et al. ${ }^{99}$

\section{SRAGE}

RAGE activation may be prevented by SRAGE which competes with RAGE for the same ligands and therefore fewer amounts of ligands are spared to interact with RAGE to activate intracellular signaling and produce harmful effects. sRAGE can prevent RAGE signal transduction directly by preventing the homodimerization of RAGE on cell surface binding with ligands and does not activate intracellular signaling. ${ }^{100}$

\section{Raising the Levels of SRAGE}

Since sRAGE competes with RAGE for AGE ligand and since interaction of sRAGE with AGE does not activate intracellular signaling, raising the levels of sRAGE would have beneficial effects in patients with PH. Certain drugs commonly used in patients for cardiovascular diseases and diabetes raise the levels of sRAGE. Statins (pitavastatin and pravastatin ${ }^{101}$ ) in humans; (atorvastatin, fluvastatin, and lovastatin ${ }^{102}$ ) in isolated cell lines; angiotensin converting enzyme inhibitors ramipril $^{103}$ in serum of diabetic rats and perindopril ${ }^{104}$ in serum of type- 1 diabetics; and the antidiabetic drug, rosiglitazone, elevated the levels of sRAGE. Vitamin D elevates the serum levels of sRAGE in women with POCS. ${ }^{105}$ Exogenous administration of sRAGE has been demonstrated to reduce/reverse RAGE-mediated pathology in the animal model. sRAGE administration exogenously suppressed the development of atherosclerosis and restenosis, prevented destabilization of vulnerable plaques and reduced ischemiareperfusion-induced myocardial injury. ${ }^{26}$ Park et al ${ }^{106}$ reported that sRAGE totally prevented the development of atherosclerosis in apolipoprotein-E (Apoe)-deficient mice independent of glycemia and lipids. sRAGE markedly reduced the carotid artery restenosis in mice, ${ }^{107}$ and AGEinduced vasculopathy in diabetic rats. ${ }^{108}$ Administration of sRAGE either peripherally or directly to organs has been shown to reverse some of RAGE-mediated pathological effects in vivo. ${ }^{109}$ sRAGE given intraperitoneally in the dose of 20 microgram/day for 14 days in hypoxia-induced $\mathrm{PH}$ in mice reduced hypoxia-induced $\mathrm{PH}$, right ventricular systolic pressure and peripheral vascular resistance but did not affect distal pulmonary vascular remodeling. ${ }^{110}$ These data suggest that SRAGE could prevent, regress, and slow the progression of $\mathrm{PH}$. 


\section{Antioxidants}

As mentioned earlier, ${ }^{72,73}$ ROS plays a major role in the development of $\mathrm{PH}$. Considering that antioxidants may be an option for the treatment of PH. In experimental studies, it has been shown that antioxidants attenuate the remodeling of pulmonary vasculature. ${ }^{111,112}$ In a clinical trial, melatonin administered in the dose of $3 \mathrm{mg} / \mathrm{kg}$, orally for 3 months to patients with moderate to severe COPD, reduced oxidative stress, and improved dyspnea. ${ }^{113}$ Melatonin suppressed hypoxia-induced $\mathrm{PH}$ and reduced the proliferation of smooth muscle cells of pulmonary artery in rats. ${ }^{114}$ Melatonin $(6 \mathrm{mg} / \mathrm{kg})$ administered orally to monocrotaline treated rats (model of pulmonary hypertension), improved lung edema, reduced right ventricular (RV) hypertrophy and improved RV function and reduced interstitial cardiac and lung fibrosis, and oxidative stress. ${ }^{115}$ Details of melatonin for possible treatment of $\mathrm{PH}$ are given by Maarman. ${ }^{115}$ There are numerous enzymatic and other nonenzymatic oxidants that can be of value in the adjunct therapy of PH. Attention should be given to some of the vitamins, such as vitamins $\mathrm{E}, \mathrm{C}$, and D, for use as an antioxidants in $\mathrm{PH}$ patients. These vitamins have some beneficial effects in patients with Alzheimer's disease.

\section{Discussion}

Serum/plasma levels AGE have not been measured in patients with PH. However the levels are elevated in the diseases where PH occurs. ${ }^{36-42}$ It would be useful if the levels of AGE were measured because this would help in the assessment of AGE-RAGE stress which is measured as AGE/sRAGE. ${ }^{35}$ This ratio is a risk factor for disease and a high ratio indicates the presence of disease and its complications. ${ }^{35}$ Levels of RAGE have been reported to be elevated in patients with $\mathrm{PH}^{44-46}$ Interaction of elevated levels of AGE and RAGE would increase the production of ROS, proinflammatory cytokines, and vascular remodeling. Serum levels of sRAGE are variable in patients with $\mathrm{PH}$ and associated diseases. Plasma levels of SRAGE have been reported to be higher in patients with $\mathrm{PH}^{43,49}$ while the levels are lower in patients with lung disease without $\mathrm{PH}^{38,47,48}$ as compared with controls. As stated earlier, sRAGE is cytoprotective and hence, high levels of SRAGE would have protected the development of PH but it did not do so. This is possible because both AGE and sRAGE are elevated in patients with PH but the elevation of AGE may be greater than the elevation of sRAGE. If this happens then more AGE is available to interact with RAGE to induce PH and its complication. Recently Prasad $^{116,117}$ has reported that AGE/sRAGE, but not AGE or sRAGE individually, is a risk factor/biomarker of diseases. Why not use the levels of RAGE also in this equation? RAGE levels can be measured in animal studies but in humans, it is not possible to measure cell receptor RAGE. For measurement of RAGE one has to get tissue samples. As stated earlier, AGE-RAGE stress has been defined as a shift in the balance between stressors (AGE, RAGE) and antistressors (AGE degraders, sRAGE) in favor of stressors. A simple and feasible measure of AGE-RAGE stress (AGE/sRAGE) for clinical practice has been developed by Prasad and Mishra. ${ }^{35} \mathrm{~A}$ high ratio of AGE/SRAGE indicates the presence of disease and its complication.

From the available data, it appears that AGE-RAGE stress is involved in the pathogenesis of PH. To date, the studies that have been performed are mostly related to RAGE in the pathogenesis of $\mathrm{PH}$. The serum levels of AGE and sRAGE should be measured in the same patient so that AGE-stress can be assessed. Measurement of AGE or sRAGE individually does not provide a complete picture in the pathogenesis of PH. Plasma levels of AGE and SRAGE, and tissue levels of RAGE should be measured in animal models of $\mathrm{PH}$ to provide a role of AGE-RAGE stress in the pathogenesis of PH. A robust clinical trial is needed for identifying the role of AGE-RAGE stress in the pathogenesis of $\mathrm{PH}$.

Considering the involvement of the AGE-RAGE axis in the development of $\mathrm{PH}$, the treatment should include reduction in AGE and RAGE levels and elevation of sRAGE levels in PH patients which have been discussed earlier in detail by the author in this manuscript. Reduction of AGE levels should be an adjunct therapy along with any other treatments for PH. Consumption of acidic food, vitamins B1, B6, C, D, and E should be encouraged because these agents attenuate the synthesis of AGE. New drugs should be developed to block RAGE ligand binding. Human recombinant SRAGE should be developed for human use. Use of antioxidant vitamins, especially vitamins $C$ and $E$ should not be ignored. Combined use of drugs that reduce AGE levels and expression of RAGE, blocker of RAGE ligand binding, and elevation of sRAGE levels would block all pathways of the AGE-RAGE axis and hence, would be more effective than a single pathway blocker. While remembering that AGE-RAGE stress may not be the only risk factor for PH, one should not expect that.

\section{Conclusions}

The data, to date, suggest that AGE-RAGE stress may be involved in the pathogenesis of PH. AGE and its interaction with RAGE induce pulmonary vascular hypertrophy through proliferation of smooth muscle cells, accumulation of ECM and suppression of autophagy. AGE-RAGE-induced increase in ROS modulates cellular proliferation, attenuates apoptosis, and constricts the blood vessels. Increased stiffness of the artery due to vascular hypertrophy and vasoconstriction results in pulmonary hypertension. The data also suggest that the reduction in consumption and formation of AGE, suppression of RAGE expression, blockage of RAGE ligand binding, elevation of sRAGE, and antioxidant may be a novel therapeutic target for prevention, regression, and slowing of progression of $\mathrm{PH}$.

\section{Disclosure \\ None.}

Conflict of Interest

None. 


\section{References}

1 Simonneau G, Gatzoulis MA, Adatia I, et al. Updated clinical classification of pulmonary hypertension. J Am Coll Cardiol 2013;62(25, Suppl):D34-D41

2 Sysol JR, Machado RF. Classification and pathophysiology of pulmonary hypertension. Continuing Cardiol Education 2018;4(1)

3 Machicao VI, Balakrishnan M, Fallon MB. Pulmonary complications in chronic liver disease. Hepatology 2014;59(04):1627-1637

4 Wijeratne DT, Lajkosz K, Brogly SB, et al. Increasing incidence and prevalence of world health organization groups 1 to 4 pulmonary hypertension: a population-based cohort study in Ontario, Canada. Circ Cardiovasc Qual Outcomes 2018;11(02):e003973

5 Prasad K, Mishra M. Do advanced glycation end products and its receptors play a role in the pathophysiology of hypertension? Int J Angiol 2017;26(01):1-11

6 Prasad K. Pathophysiology and medical treatment of carotid artery stenosis. Int J Angiol 2015;24(03):158-172

7 Prasad K, Tiwari S. Therapeutic interventions for advanced glycation end products and its receptor-mediated cardiovascular disease. Curr Pharm Des 2017;23(06):937-943

8 McGoon MD, Benza RL, Escribano-Subias P, et al. Pulmonary arterial hypertension: epidemiology and registries. J Am Coll Cardiol 2013;62(25, Suppl):D51-D59

9 Peacock AJ, Murphy NF, McMurray JJV, Caballero L, Stewart S. An epidemiological study of pulmonary arterial hypertension. Eur Respir J 2007;30(01):104-109

10 Hoeper MM, Huscher D, Pittrow D. Incidence and prevalence of pulmonary arterial hypertension in Germany. Int J Cardiol 2016; 203:612-613

11 Ghio S, Gavazzi A, Campana C, et al. Independent and additive prognostic value of right ventricular systolic function and pulmonary artery pressure in patients with chronic heart failure. J Am Coll Cardiol 2001;37(01):183-188

12 Thabut G, Dauriat G, Stern JB, et al. Pulmonary hemodynamics in advanced COPD candidates for lung volume reduction surgery or lung transplantation. Chest 2005;127(05):1531-1536

13 Chaouat A, Bugnet AS, Kadaoui N, et al. Severe pulmonary hypertension and chronic obstructive pulmonary disease. Am J Respir Crit Care Med 2005;172(02):189-194

14 Lettieri CJ, Nathan SD, Barnett SD, Ahmad S, Shorr AF. Prevalence and outcomes of pulmonary arterial hypertension in advanced idiopathic pulmonary fibrosis. Chest 2006;129(03):746-752

15 Escribano-Subias P, Blanco I, López-Meseguer M, et al; REHAP investigators. Survival in pulmonary hypertension in Spain: insights from the Spanish registry. Eur Respir J 2012;40(03):596-603

16 Pengo V, Lensing AW, Prins MH, et al; Thromboembolic Pulmonary Hypertension Study Group. Incidence of chronic thromboembolic pulmonary hypertension after pulmonary embolism. N Engl J Med 2004;350(22):2257-2264

17 Shorr AF, Helman DL, Davies DB, Nathan SD. Pulmonary hypertension in advanced sarcoidosis: epidemiology and clinical characteristics. Eur Respir J 2005;25(05):783-788

18 Rich JD, Rich S. Clinical diagnosis of pulmonary hypertension. Circulation 2014;130(20):1820-1830

19 Galiè N, Hoeper MM, Humbert M, et al; ESC Committee for Practice Guidelines (CPG). Guidelines for the diagnosis and treatment of pulmonary hypertension. Eur Heart J 2009;30 (20):2493-2537

20 Farber HW, Loscalzo J. Pulmonary arterial hypertension. N Engl J Med 2004;351(16):1655-1665

21 Yuan XJ, Tod ML, Rubin LJ, Blaustein MP. Contrasting effects of hypoxia on tension in rat pulmonary and mesenteric arteries. Am J Physiol 1990;259(2, Pt. 2):H281-H289

22 Humbert M, Morrell NW, Archer SL, et al. Cellular and molecular pathobiology of pulmonary arterial hypertension. J Am Coll Cardiol 2004;43(12, Suppl. S):13s-24s

23 Yuan JX, Rubin LJ. Pathogenesis of pulmonary arterial hypertension: the need for multiple hits. Circulation 2005;111:534-538
24 Herve P, Humbert M, Sitbon O, et al. Pathobiology of pulmonary hypertension. The role of platelets and thrombosis. Clin Chest Med 2001;22(03):451-458

25 Aytekin M, Aulak KS, Haserodt S, et al. Abnormal platelet aggregation in idiopathic pulmonary arterial hypertension: role of nitric oxide. Am J Physiol Lung Cell Mol Physiol 2012; 302(06):L512-L520

26 Prasad K. Soluble receptor for advanced glycation end products (sRAGE) and cardiovascular disease. Int J Angiol 2006;15:57-68

27 Bucala R, Cerami A. Advanced glycosylation: chemistry, biology, and implications for diabetes and aging. Adv Pharmacol 1992; 23:1-34

28 Wautier MP, Chappey O, Corda S, Stern DM, Schmidt AM, Wautier JL. Activation of NADPH oxidase by AGE links oxidant stress to altered gene expression via RAGE. Am J Physiol Endocrinol Metab 2001;280(05):E685-E694

29 Gloire G, Legrand-Poels S, Piette J. NF-kappaB activation by reactive oxygen species: fifteen years later. Biochem Pharmacol 2006;72(11):1493-1505

30 Reznikov LL, Waksman J, Azam T, et al. Effect of advanced glycation end products on endotoxin-induced TNF-alpha, IL1 beta and IL-8 in human peripheral blood mononuclear cells. Clin Nephrol 2004;61(05):324-336

31 Schmidt AM, Yan SD, Brett J, Mora R, Nowygrod R, Stern D. Regulation of human mononuclear phagocyte migration by cell surface-binding proteins for advanced glycation end products. J Clin Invest 1993;91(05):2155-2168

32 Tam XHL, Shiu SWM, Leng L, Bucala R, Betteridge DJ, Tan KCB. Enhanced expression of receptor for advanced glycation endproducts is associated with low circulating soluble isoforms of the receptor in Type 2 diabetes. Clin Sci (Lond) 2011;120(02):81-89

33 Yonekura H, Yamamoto Y, Sakurai S, et al. Novel splice variants of the receptor for advanced glycation end-products expressed in human vascular endothelial cells and pericytes, and their putative roles in diabetes-induced vascular injury. Biochem J 2003; 370(Pt. 3):1097-1109

34 Geroldi D, Falcone C, Emanuele E. Soluble receptor for advanced glycation end products: from disease marker to potential therapeutic target. Curr Med Chem 2006;13(17):1971-1978

35 Prasad K, Mishra M. AGE-RAGE stress, stressors, and antistressors in health and disease. Int J Angiol 2018;27(01):1-12

36 Gopal P, Reynaert NL, Scheijen JLJM, et al. Plasma advanced glycation end-products and skin autofluorescence are increased in COPD. Eur Respir J 2014;43(02):430-438

$37 \mathrm{Wu}$ L, Ma L, Nicholson LFB, Black PN. Advanced glycation end products and its receptor (RAGE) are increased in patients with COPD. Respir Med 2011;105(03):329-336

38 Hoonhorst SJM, Lo Tam Loi AT, Hartman JE, et al. Advanced glycation end products in the skin are enhanced in COPD. Metabolism 2014;63(09):1149-1156

39 Berg TJ, Snorgaard O, Faber J, et al. Serum levels of advanced glycation end products are associated with left ventricular diastolic function in patients with type 1 diabetes. Diabetes Care 1999;22(07):1186-1190

40 Linssen PBC, Henry RM, Schalkwijk CG, et al. Serum advanced glycation endproducts are associated with left ventricular dysfunction in normal glucose metabolism but not in type 2 diabetes: The Hoorn Study. Diab Vasc Dis Res 2016;13(04):278-285

41 Hegab Z, Gibbons S, Neyses L, Mamas MA. Role of advanced glycation end products in cardiovascular disease. World J Cardiol 2012;4(04):90-102

42 Koyama Y, Takeishi Y, Arimoto T, et al. High serum level of pentosidine, an advanced glycation end product (AGE), is a risk factor of patients with heart failure. J Card Fail 2007;13(03): 199-206

43 Moser B, Megerle A, Bekos C, et al. Local and systemic RAGE axis changes in pulmonary hypertension: CTEPH and iPAH. PLoS One 2014;9(09):e106440 
44 Jia D, He Y, Zhu Q et al. RAGE-mediated extracellular matrix proteins accumulation exacerbates HySu-induced pulmonary hypertension. Cardiovasc Res 2017;113(06):586-597

45 Abdul-Salam VB, Wharton J, Cupitt J, Berryman M, Edwards RJ, Wilkins MR. Proteomic analysis of lung tissues from patients with pulmonary arterial hypertension. Circulation 2010;122 (20):2058-2067

46 Meloche J, Courchesne A, Barrier M, et al. Critical role for the advanced glycation end-products receptor in pulmonary arterial hypertension etiology. J Am Heart Assoc 2013;2(01):e005157

47 Manichaikul A, Sun L, Borczuk AC, et al. Plasma Soluble Receptor for Advanced Glycation End Products in Idiopathic Pulmonary Fibrosis. Ann Am Thorac Soc 2017;14(05):628-635

48 Yonchuk JG, Silverman EK, Bowler RP, et al. Circulating soluble receptor for advanced glycation end products (sRAGE) as a biomarker of emphysema and the RAGE axis in the lung. Am J Respir Crit Care Med 2015;192(07):785-792

49 Suzuki S, Nakazato K, Sugimoto K, et al. Receptor for Aavanced glycation end-products and high-mobility group box 1 in patients with pulmonary hypertension. Int Heart J 2016;57(02):234-240

50 Schmidt AM, Hasu M, Popov D, et al. Receptor for advanced glycation end products (AGEs) has a central role in vessel wall interactions and gene activation in response to circulating AGE proteins. Proc Natl Acad Sci U S A 1994;91(19):8807-8811

51 Tanaka S, Avigad G, Brodsky B, Eikenberry EF. Glycation induces expansion of the molecular packing of collagen. J Mol Biol 1988; 203(02):495-505

52 Striker LJ, Striker GE. Administration of AGEs in vivo induces extracellular matrix gene expression. Nephrol Dial Transplant 1996;11(Suppl 5):62-65

53 Hogan M, Cerami A, Bucala R. Advanced glycosylation endproducts block the antiproliferative effect of nitric oxide. Role in the vascular and renal complications of diabetes mellitus. J Clin Invest 1992;90(03):1110-1115

54 Rojas A, Romay S, González D, Herrera B, Delgado R, Otero K. Regulation of endothelial nitric oxide synthase expression by albumin-derived advanced glycosylation end products. Circ Res 2000;86(03):E50-E54

55 Xu B, Chibber R, Ruggiero D, Kohner E, Ritter J, Ferro A. Impairment of vascular endothelial nitric oxide synthase activity by advanced glycation end products. FASEB J 2003;17(10):1289-1291

56 Goldin A, Beckman JA, Schmidt AM, Creager MA. Advanced glycation end products: sparking the development of diabetic vascular injury. Circulation 2006;114(06):597-605

57 Yamagishi S, Fujimori H, Yonekura H, Yamamoto Y, Yamamoto H. Advanced glycation endproducts inhibit prostacyclin production and induce plasminogen activator inhibitor-1 in human microvascular endothelial cells. Diabetologia 1998;41(12):1435-1441

58 Quehenberger P, Bierhaus A, Fasching P, et al. Endothelin 1 transcription is controlled by nuclear factor-kappaB in AGE-stimulated cultured endothelial cells. Diabetes 2000;49(09):1561-1570

59 Ma M, Guo X, Chang Y, et al. Advanced glycation end products promote proliferation and suppress autophagy via reduction of Cathepsin D in rat vascular smooth muscle cells. Mol Cell Biochem 2015;403(1,2):73-83

$60 \mathrm{Li} \mathrm{C}$, Chang Y, Li Y, et al. Advanced glycation end products promote the proliferation and migration of primary rat vascular smooth muscle cells via the upregulation of BAG3. Int J Mol Med 2017;39(05):1242-1254

61 Yuan X, Zhang Z, Gong K, Zhao P, Qin J, Liu N. Inhibition of reactive oxygen species/extracellular signal-regulated kinases pathway by pioglitazone attenuates advanced glycation end productsinduced proliferation of vascular smooth muscle cells in rats. Biol Pharm Bull 2011;34(05):618-623

62 Greenway S, van Suylen RJ, Du Marchie Sarvaas G, et al. S100A4/ Mts1 produces murine pulmonary artery changes resembling plexogenic arteriopathy and is increased in human plexogenic arteriopathy. Am J Pathol 2004;164(01):253-262
63 Ciuclan L, Bonneau O, Hussey M, et al. A novel murine model of severe pulmonary arterial hypertension. Am J Respir Crit Care Med 2011;184(10):1171-1182

64 Ranzato E, Patrone M, Pedrazzi M, Burlando B. Hmgb1 promotes wound healing of 3T3 mouse fibroblasts via RAGE-dependent ERK1/2 activation. Cell Biochem Biophys 2010;57(01):9-17

65 Rafikova O, McBride ML, Langlais PR, Rafikov R. Receptor for advanced glycation end products (RAGE) regulates metabolic reprogramming induced over-proliferation in pulmonary hypertension. Am J Respir Crit Care Med 2018;197:A4613

66 Nakamura K, Sakaguchi M, Matsubara H, et al. Crucial role of RAGE in inappropriate increase of smooth muscle cells from patients with pulmonary arterial hypertension. PLoS One 2018; 13(09): 0203046

67 Bharadwaj LA, Prasad K. Mechanism of superoxide anioninduced modulation of vascular tone. Int J Angiol 2002;11:23-29

68 Bharadwaj L, Prasad K. Mediation of H2O2-induced vascular relaxation by endothelium-derived relaxing factor. Mol Cell Biochem 1995;149-150:267-270

69 Prasad K, Kalra J, Chaudhary AK, Debnath D. Effect of polymorphonuclear leukocyte-derived oxygen free radicals and hypochlorous acid on cardiac function and some biochemical parameters. Am Heart J 1990;119(3, Pt. 1):538-550

70 Prasad K, Kalra J, Chan WP, Chaudhary AK. Effect of oxygen free radicals on cardiovascular function at organ and cellular levels. Am Heart J 1989;117(06):1196-1202

71 Owen CA. Proteinases and oxidants as targets in the treatment of chronic obstructive pulmonary disease. Proc Am Thorac Soc 2005;2(04):373-385, discussion 394-395

72 Aggarwal S, Gross CM, Sharma S, Fineman JR, Black SM. Reactive oxygen species in pulmonary vascular remodeling. Compr Physiol 2013;3(03):1011-1034

73 Jernigan NL, Naik JS, Weise-Cross L, et al. Contribution of reactive oxygen species to the pathogenesis of pulmonary arterial hypertension. PLoS One 2017;12(06):e0180455

74 Weisenberger J. Foods high in AGEs. Available at: http://www. diabetesforecast.org/2014/11-nov/foods-high-in-ages.html. Accessed 2014

75 Uribarri J, Woodruff S, Goodman S, et al. Advanced glycation end products in foods and a practical guide to their reduction in the diet. J Am Diet Assoc 2010;110(06):911-16.e12

76 Uribarri J, Cai W, Sandu O, Peppa M, Goldberg T, Vlassara H. Dietderived advanced glycation end products are major contributors to the body's AGE pool and induce inflammation in healthy subjects. Ann N Y Acad Sci 2005;1043:461-466

77 Prasad K, Dhar I, Caspar-Bell G, Prasad K, Dhar I, Caspar-Bell G. Role of advanced glycation end products and its receptors in the pathogenesis of cigarette smoke-induced cardiovascular disease. Int J Angiol 2015;24(02):75-80

78 Hammes HP, Du X, Edelstein D, et al. Benfotiamine blocks three major pathways of hyperglycemic damage and prevents experimental diabetic retinopathy. Nat Med 2003;9(03): 294-299

79 Metz TO, Alderson NL, Thorpe SR, Baynes JW. Pyridoxamine, an inhibitor of advanced glycation and lipoxidation reactions: a novel therapy for treatment of diabetic complications. Arch Biochem Biophys 2003;419(01):41-49

80 Subratty AH, Aukburally N, Jowaheer V, Joonus N. Vitamin C and urea inhibit the formation of advanced glycation end products in vitro. Nutr Food Sci 2010;40:456-465

81 Salum E, Kals J, Kampus P, et al. Vitamin D reduces deposition of advanced glycation end-products in the aortic wall and systemic oxidative stress in diabetic rats. Diabetes Res Clin Pract 2013;100 (02):243-249

82 Baragetti I, Furiani S, Vettoretti S, et al. Role of vitamin E-coated membrane in reducing advanced glycation end products in hemodialysis patients: a pilot study. Blood Purif 2006;24(04): 369-376 
83 Klebanov GI, Teselkin YuO, Babenkova IV, et al. Effect of carnosine and its components on free-radical reactions. Membr Cell Biol 1998;12(01):89-99

84 Price DL, Rhett PM, Thorpe SR, Baynes JW. Chelating activity of advanced glycation end-product inhibitors. J Biol Chem 2001; 276(52):48967-48972

85 Hipkiss AR. Carnosine and protein carbonyl groups: a possible relationship. Biochemistry (Mosc) 2000;65(07):771-778

86 Ramful D, Tarnus E, Rondeau P, Da Silva CR, Bahorun T, Bourdon E. Citrus fruit extracts reduce advanced glycation end products (AGEs)- and $\mathrm{H}_{2} \mathrm{O}_{2}$-induced oxidative stress in human adipocytes. J Agric Food Chem 2010;58(20):11119-11129

87 Liu W, Ma H, Frost L, Yuan T, Dain JA, Seeram NP. Pomegranate phenolics inhibit formation of advanced glycation endproducts by scavenging reactive carbonyl species. Food Funct 2014;5(11): 2996-3004

88 Mannervik B. Molecular enzymology of the glyoxalase system. Drug Metabol Drug Interact 2008;23(1,2):13-27

89 Shinohara M, Thornalley PJ, Giardino I, et al. Overexpression of glyoxalase-I in bovine endothelial cells inhibits intracellular advanced glycation endproduct formation and prevents hyperglycemia-induced increases in macromolecular endocytosis. J Clin Invest 1998;101(05):1142-1147

90 Cai W, He JC, Zhu L, Lu C, Vlassara H. Advanced glycation end product (AGE) receptor 1 suppresses cell oxidant stress and activation signaling via EGF receptor. Proc Natl Acad Sci U S A 2006;103(37):13801-13806

91 Cuccurullo C, Iezzi A, Fazia ML, et al. Suppression of RAGE as a basis of simvastatin-dependent plaque stabilization in type 2 diabetes. Arterioscler Thromb Vasc Biol 2006;26(12):2716-2723

92 Xu L, Zang P, Feng B, Qian Q. Atorvastatin inhibits the expression of RAGE induced by advanced glycation end products on aortas in healthy Sprague-Dawley rats. Diabetol Metab Syndr 2014;6 (01):102

93 Nakamura K, Yamagishi S, Nakamura Y, et al. Telmisartan inhibits expression of a receptor for advanced glycation end products (RAGE) in angiotensin-II-exposed endothelial cells and decreases serum levels of soluble RAGE in patients with essential hypertension. Microvasc Res 2005;70(03):137-141

94 Fan Q Liao J, Kobayashi M, et al. Candesartan reduced advanced glycation end-products accumulation and diminished nitrooxidative stress in type 2 diabetic KK/Ta mice. Nephrol Dial Transplant 2004;19(12):3012-3020

95 Marx N, Walcher D, Ivanova N, et al. Thiazolidinediones reduce endothelial expression of receptors for advanced glycation end products. Diabetes 2004;53(10):2662-2668

96 Yamagishi S, Takeuchi M. Nifedipine inhibits gene expression of receptor for advanced glycation end products (RAGE) in endothelial cells by suppressing reactive oxygen species generation. Drugs Exp Clin Res 2004;30(04):169-175

97 Lin J, Tang Y, Kang Q, Feng Y, Chen A. Curcumin inhibits gene expression of receptor for advanced glycation end-products (RAGE) in hepatic stellate cells in vitro by elevating PPARr activity and attenuating oxidative stress. Br J Pharmacol 2012; 166(08):2212-2227

98 TransTech Pharma LLC. Available at: https://bciq.biocentury.com/ companies/transtech_pharma_llc. Accessed on March 25, 2019

99 Bongarzone S, Savickas V, Luzi F, Gee AD. Targeting the Receptor for Advanced Glycation Endproducts (RAGE): A Medicinal Chemistry Perspective. J Med Chem 2017;60(17):7213-7232

100 Zong H, Madden A, Ward M, Mooney MH, Elliott CT, Stitt AW. Homodimerization is essential for the receptor for advanced glycation end products (RAGE)-mediated signal transduction. J Biol Chem 2010;285(30):23137-23146

101 Nozue T, Yamagishi S-I, Takeuchi M, et al. Effect of statins on the serum soluble form of receptor for advanced glycation end-products and its association with coronary atherosclerosis in patients with angina pectoris. IJC Metab Endocr 2014; 4:47-52

102 Quade-Lyssy P, Kanarek AM, Baiersdörfer M, Postina R, Kojro E. Statins stimulate the production of a soluble form of the receptor for advanced glycation end products. J Lipid Res 2013;54(11): 3052-3061

103 Forbes JM, Thorpe SR, Thallas-Bonke V, et al. Modulation of soluble receptor for advanced glycation end products by angiotensin-converting enzyme-1 inhibition in diabetic nephropathy. J Am Soc Nephrol 2005;16(08):2363-2372

104 Tan KCB, Chow WS, Tso AWK, et al. Thiazolidinedione increases serum soluble receptor for advanced glycation end-products in type 2 diabetes. Diabetologia 2007;50(09):1819-1825

105 Irani M, Minkoff H, Seifer DB, Merhi Z. Vitamin D increases serum levels of the soluble receptor for advanced glycation end products in women with PCOS.J Clin Endocrinol Metab 2014;99(05):E886-E890

106 Park L, Raman KG, Lee KJ, et al. Suppression of accelerated diabetic atherosclerosis by the soluble receptor for advanced glycation endproducts. Nat Med 1998;4(09):1025-1031

107 Sakaguchi T, Yan SF, Yan SD, et al. Central role of RAGE-dependent neointimal expansion in arterial restenosis. J Clin Invest 2003;111(07):959-972

108 Wautier JL, Zoukourian C, Chappey O, et al. Receptor-mediated endothelial cell dysfunction in diabetic vasculopathy. Soluble receptor for advanced glycation end products blocks hyperpermeability in diabetic rats. J Clin Invest 1996;97(01):238-243

109 Santilli F, Vazzana N, Bucciarelli LG, Davì G. Soluble forms of RAGE in human diseases: clinical and therapeutical implications. Curr Med Chem 2009;16(08):940-952

110 Vonk-Noordegraaf A, Haddad F, Chin KM, et al. Right heart adaptation to pulmonary arterial hypertension: physiology and pathobiology. J Am Coll Cardiol 2013;62(25, Suppl.):D22-D33

111 Ryan JJ, Archer SL. The right ventricle in pulmonary arterial hypertension: disorders of metabolism, angiogenesis and adrenergic signaling in right ventricular failure. Circ Res 2014;115 (01):176-188

112 de Matos Cavalcante AG, de Bruin PF, de Bruin VM, et al. Melatonin reduces lung oxidative stress in patients with chronic obstructive pulmonary disease: a randomized, double-blind, placebo-controlled study. J Pineal Res 2012;53(03):238-244

113 Jin H, Wang Y, Zhou L, et al. Melatonin attenuates hypoxic pulmonary hypertension by inhibiting the inflammation and the proliferation of pulmonary arterial smooth muscle cells. J Pineal Res 2014;57(04):442-450

114 Maarman G, Blackhurst D, Thienemann F, et al. Melatonin as a preventive and curative therapy against pulmonary hypertension. J Pineal Res 2015;59(03):343-353

115 Maarman GJ. Natural antioxidants as potential therapy, and a promising role for melatonin against pulmonary hypertension. Adv Exp Med Biol 2017;967:161-178. doi:10.1007/978-3-31963245-2-10

116 Prasad K. Low levels of serum soluble receptors for advanced glycation end products, biomarkers for disease state: myth or reality. Int J Angiol 2014;23(01):11-16

117 Prasad K. Is there any evidence that AGE/sRAGE is a universal biomarker/risk marker for diseases? Mol Cell Biochem 2019;451 $(1,2): 139-144$ 